\title{
Blood Pressure Increase during Oxygen Supplementation in Chronic Kidney Disease Patients Is Mediated by Vasoconstriction Independent of Baroreflex Function
}

René van der Bel ${ }^{1}$, Müşerref Çalişkan ${ }^{1}$, Robert A. van Hulst ${ }^{2}$, Johannes J. van Lieshout ${ }^{1,3}$, Erik S. G. Stroes ${ }^{1}$ and C. T. Paul Krediet ${ }^{1 *}$

'Department of Internal Medicine, Academic Medical Center at the University of Amsterdam, Amsterdam, Netherlands, ${ }^{2}$ Department of Hyperbaric Medicine, Academic Medical Center at the University of Amsterdam, Amsterdam, Netherlands, ${ }^{3}$ MRC-Arthritis Research UK Centre of Musculoskeletal Ageing Research, School of Life Sciences, Medical School, University of Nottingham, Queen's Medical Centre, Nottingham, UK

OPEN ACCESS

Edited by:

Fredrik Palm

Uppsala University, Sweden

Reviewed by:

Heather Drummond,

University of Mississippi Medical Center School of Dentistry, USA

Anand R. Nair,

University of lowa, USA

Daniela Patinha,

University of Bristol, UK

${ }^{*}$ Correspondence:

C. T. Paul Krediet

c.t.krediet@amc.uva.n

Specialty section

This article was submitted to Renal and Epithelial Physiology, a section of the journa

Frontiers in Physiology

Received: 29 November 2016 Accepted: 13 March 2017 Published: 30 March 2017

Citation:

van der Bel $R$, Çalișkan M, van

Hulst RA, van Lieshout JJ,

Stroes ESG and Krediet CTP (2017)

Blood Pressure Increase during

Oxygen Supplementation in Chronic Kidney Disease Patients Is Mediated by Vasoconstriction Independent of

Baroreflex Function.

Front. Physiol. 8:186

doi: 10.3389/fphys.2017.00186
Renal hypoxia is thought to be an important pathophysiological factor in the progression of chronic kidney disease (CKD) and the associated hypertension. In a previous study among CKD patients, supplementation with 100\% oxygen reduced sympathetic nerve activity (SNA) and lowered blood pressure (BP). We aimed to assess the underlying haemodynamic modulation and hypothesized a decreased systemic vascular resistance (SVR). To that end, 19 CKD patients were studied during 15-min intervals of increasing partial oxygen pressure $\left(\mathrm{ppO}_{2}\right)$ from room air $(0.21 \mathrm{ATA})$ to 1.0 ATA and further up to 2.4 ATA, while continuously measuring finger arterial blood pressure (Finapres). Off-line, we derived indexes of SVR, cardiac output $(\mathrm{CO})$ and baroreflex sensitivity from the continuous BP recordings (Modelflow). During oxygen supplementation, systolic, and diastolic BP both increased dose-dependently from $128 \pm 24$ and $72 \pm 19 \mathrm{mmHg}$ respectively at baseline to $141 \pm 23(p<0.001)$ and $80 \pm 21 \mathrm{mmHg}(p<0.001)$ at 1.0 ATA oxygen. Comparing baseline and 1.0 ATA oxygen, SVR increased from $1440 \pm 546$ to $1745 \pm 710 \mathrm{dyn} \cdot \mathrm{s} / \mathrm{cm}^{5}$ ( $p=0.009$ ), heart rate decreased from $60 \pm 8$ to $58 \pm 6 \mathrm{bpm}$ $(p<0.001)$ and $\mathrm{CO}$ from $5.0 \pm 1.3$ to $4.6 \pm 1.1 \mathrm{~L} / \mathrm{min}(p=0.02)$. Baroreflex sensitivity remained unchanged ( $13 \pm 13$ to $15 \pm 12 \mathrm{~ms} / \mathrm{mmHg}$ ). These blood pressure effects were absent in a negative control group of eight young healthy subjects. We conclude that oxygen supplementation in CKD patients causes a non-baroreflex mediated increased in SVR and blood pressure.

Keywords: chronic kidney disease, hypertension, hyperbaric oxygen supplementation, renal hypoxia, systemic vascular resistance, cardiac output

\section{INTRODUCTION}

Hypertension is a hallmark of chronic kidney disease (CKD). There is substantial evidence that this can be attributed to increased sympathetic nerve activity (SNA) (Converse et al., 1992; Koomans et al., 2004; Neumann et al., 2004; Herzog et al., 2008). The mechanisms underlying increased SNA in CKD are not completely understood. Several studies have reported an attenuation of SNA and 
blood pressure (BP) following bilateral nephrectomy (Medina et al., 1972; Getts et al., 2006; Gawish et al., 2010). This has founded the concept that the trigger of the enhanced central sympathetic outflow in CKD patients resides in the affected kidneys themself. Deterioration of renal oxygenation by altered renal perfusion and increased metabolic demand has been postulated as a common factor in the progression of $\mathrm{CKD}$ (Eckardt et al., 2005; Evans et al., 2013) and nephrogenic sympathetic hyperactivity and hypertension (Converse et al., 1992; Hausberg, 2002; Siddiqi et al., 2009).

In this respect, altered renal chemo-receptor activation in CKD has been studied by various groups (Hausberg and Grassi, 2007; Hering et al., 2007; Park et al., 2008). Of special interest is a study by Hering et al. who exposed CKD patients (mean serum creatinine $5.5 \pm 0.3 \mathrm{mg} / \mathrm{dL}$ ) to $100 \%$ oxygen over a non-rebreathing mask for $15 \mathrm{~min}$. This resulted in a $30 \%$ reduction in SNA accompanied by a lower pulse pressure (Hering et al., 2007). This response was absent in healthy controls and non-CKD patient populations (Kones, 2011; Stub et al., 2015). Therefore, the observed effects on sympathetic nerve activity and BP were attributed to CKD-specific hypoxiamediated renal chemo-reflex deactivation. Additional support for the existence of a kidney-derived chemo-reflex, were the observations in non-CKD sympathetically hyperactive patient groups not showing such a response (Ganz et al., 1972; Thomson et al., 2002). Thus, the haemodynamic response to oxygen supplementation appears to be uniquely different in CKD patients.

Ever since, it has been assumed that the underlying mechanism of the BP effects of oxygen supplementation in CKD patients is mediated by a decrease in sympathetic outflow leading to a reduction in systemic vascular resistance (Thukkani and Bhatt, 2013). However, so far this has never been substantiated. Therefore, we set out to revisit and further explore the concept that systemic hyperoxia suppresses vasoconstrictor activity and $\mathrm{BP}$ in $\mathrm{CKD}$ patients. Our aim was to elaborate on the haemodynamic mechanisms underlying the $\mathrm{BP}$ changes as previously reported by others. We hypothesized: (1) that the previously observed decrease in BP is the effect of a decrease in (sympathetically mediated) systemic vascular resistance (SVR), and (2) that this effect is related to the amount of oxygen provided in a dose-dependent fashion.

\section{MATERIALS AND METHODS}

\section{Participants}

We studied 19 CKD patients (14 males, 5 females; age $62 \pm 10$ years, BMI $25.7 \pm 3.7 \mathrm{~kg} / \mathrm{m}^{2}$, eGFR $23.6 \pm 7.2 \mathrm{~mL} / \mathrm{min} / 1.73$ $\mathrm{m}^{2}$ ). Of all patients, values of hemoglobin and proteinuria were available from clinical routine testing within 3 months before the study. Baseline characteristics, including medication use and disease background are given in Table 1. To verify the known hemodynamic effects of hyperoxia and thereby the accuracy of our methods, we also included a group of eight young healthy subjects (6 males and 2 females, mean age $26 \pm 3$ years, BMI $23.1 \pm 2.7 \mathrm{~kg} / \mathrm{m}^{2}$ ). The study was carried out in accordance with the Declaration of Helsinki
TABLE 1 | Baseline characteristics of the CKD patients.

\begin{tabular}{|c|c|c|}
\hline & & Patients \\
\hline Age (years) & & $62(10)$ \\
\hline Gender (m/f) & & $14 / 5$ \\
\hline Body weight (kg) & & $77(13)$ \\
\hline BMl (kg/m2) & & $25.7(3.7)$ \\
\hline Smoking status & Yes/No & $4 / 15$ \\
\hline $\begin{array}{l}\text { Systolic/diastolic blood } \\
\text { pressure }(\mathrm{mmHg})\end{array}$ & & $128(24) / 72(19)$ \\
\hline eGFR (mL/min/1.73 m2) & & $22.5(5-40)$ \\
\hline Haemoglobin (mmol/L) & & $7.9(1.3)^{*}$ \\
\hline Proteinuria (g/L) & & $0.53(0.03-2.8)$ \\
\hline \multirow[t]{5}{*}{ Renal disease } & Vascular & 10 \\
\hline & Glomerulonephritis & 4 \\
\hline & Tubulo-interstitial & 1 \\
\hline & Polycystic disease & 3 \\
\hline & Unknown & 1 \\
\hline \multirow[t]{6}{*}{ Antihypertensive medication } & Alpha blockers & 4 \\
\hline & Beta blockers & 10 \\
\hline & ACE inhibitors & 6 \\
\hline & ARBs & 8 \\
\hline & Calcium antagonists & 11 \\
\hline & Diuretics & 8 \\
\hline
\end{tabular}

Data are presented as absolute number or mean (SD) or with range in case the outcome measure is skewed. ACE, angiotensin converting enzyme. ARB, Angiotensin II receptor blocker. *Six patients used erythropoietin-analogs.

of the World Medical Association (2013). The Medical Ethics Review Committee of the Academic Medical Center (University of Amsterdam, Amsterdam, The Netherlands) approved the study protocol. Before inclusion all participants provided written informed consent.

\section{Normobaric Challenge}

After an initial baseline measurement of $15 \mathrm{~min}$ room air (RA), a non-rebreathing mask was positioned over nose and mouth. Blood pressure measurement (see below) was continued while room air, partial pressure of oxygen $\left(\mathrm{ppO}_{2}\right) 0.21$ ATA, was provided over the mask at $15 \mathrm{~L} / \mathrm{min}$ for another $15 \mathrm{~min}$. Thereafter the $\mathrm{ppO}_{2}$ in the breathing gas was increased to $50 \%$ $\mathrm{O}_{2}\left(\mathrm{ppO}_{2} 0.5\right.$ ATA) and $100 \% \mathrm{O}_{2}\left(\mathrm{ppO}_{2} 1.0\right.$ ATA) respectively again for $15 \mathrm{~min}$ at each dose (Figure 1). The oxygen dose was regulated using an air-oxygen blender (Precision Medical Inc., Northampton, USA). Patients were blinded to the dosage and were not aware when the oxygen dose was altered. Measurements were performed in a quiet room with the temperature controlled at $22^{\circ} \mathrm{C}$. During all measurements, participants remained quietly in the supine position. Patients receiving angiotensin-convertingenzyme (ACE) inhibitors and/or angiotensin II receptor blockers (ARBs) had postponed the intake of these medications until after the study visit.

\section{Hyperbaric Challenge}

In another session, subjects were exposed to hyperbaric oxygen in a hyperbaric chamber. Again, during all measurements patients 


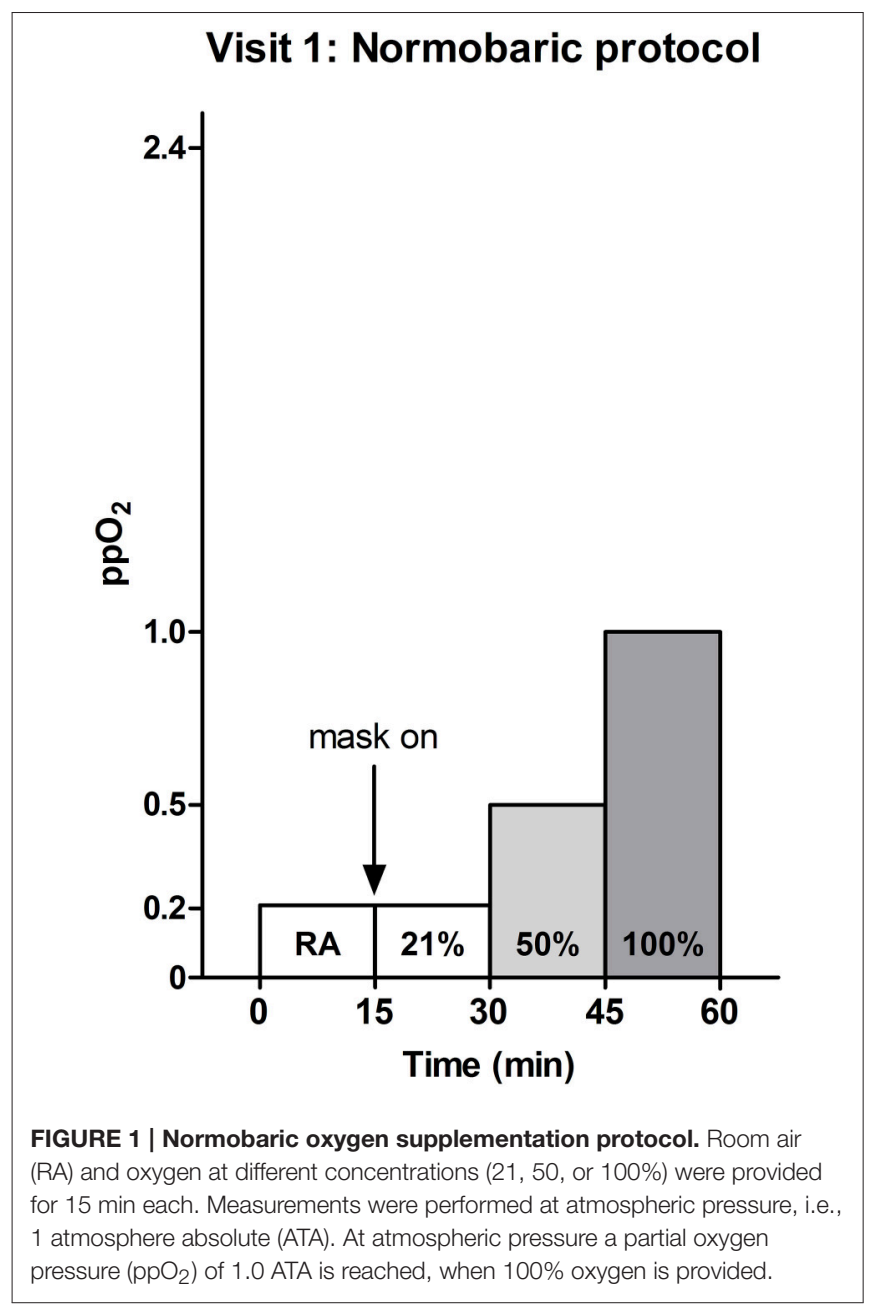

assumed a supine position. Continuous blood pressure was recorded while breathing room air (RA) at atmospheric pressure $\left(\mathrm{ppO}_{2} 0.21 \mathrm{ATA}\right)$, under hyperbaric conditions at 2.4 ATA $\left(\mathrm{ppO}_{2}\right.$ 0.5 ATA) and at 2.4 ATA during $100 \%$ oxygen supplementation $\left(\mathrm{ppO}_{2} 2.4\right.$ ATA, Figure 2).

\section{Continuous Blood Pressure Measurements and Analysis}

During all sessions, continuous blood pressure was measured using finger arterial photo-plethysmography (Portapres ${ }^{\mathrm{TM}}$, Finapres Medical Systems, Amsterdam, The Netherlands). The device has been validated for use in CKD patients (Imholz et al., 1998). The appropriate size finger cuff was positioned around the mid-phalanx of the left middle finger for all recordings and passively positioned at heart level. The system had been adapted for use under hyperbaric conditions as previously reported in detail (van der Bel et al., 2016).

The finger arterial pressure signal was recorded at $100 \mathrm{~Hz}$ and analyzed off-line using the Modelflow algorithm (Beatscope ${ }^{\circledR}$ version 1.1a, Finapres Medical Systems, Amsterdam, The Netherlands). This algorithm provides a validated beat-to-beat estimate of left ventricular stroke volume (SV), based on a

\section{Visit 2: Hyperbaric protocol}

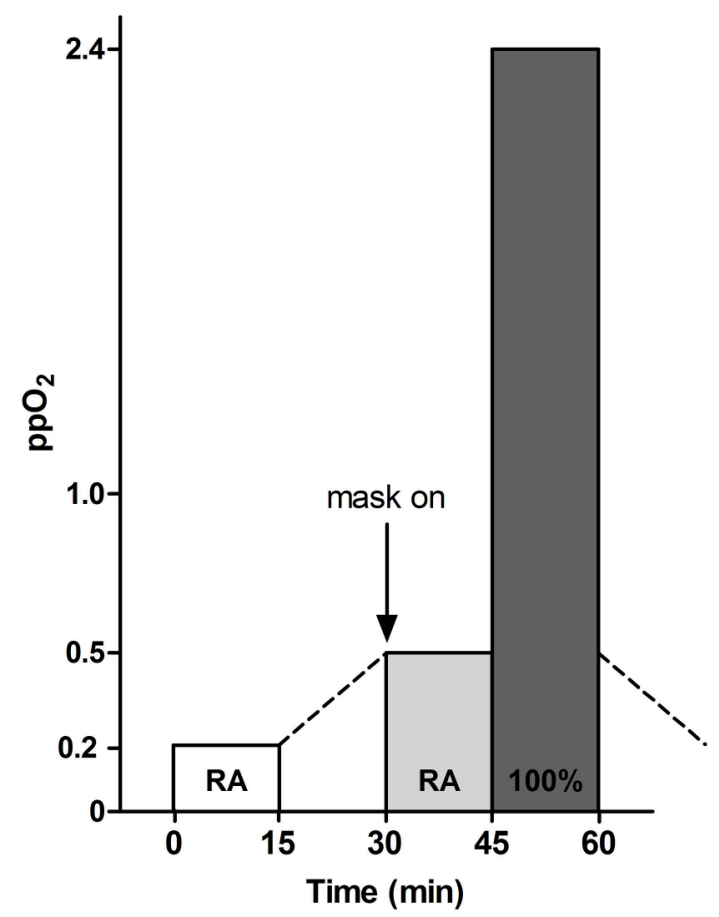

FIGURE 2 | Hyperbaric oxygen supplementation protocol. Normobaric and hyperbaric room air (RA) and hyperbaric oxygen (100\%) were provided for 15 min each. Measurements were performed at atmospheric pressure (1 ATA) and under hyperbaric conditions (2.4 ATA). At atmospheric pressure a partial oxygen pressure $\left(\mathrm{ppO}_{2}\right)$ of 1.0 ATA was reached, when $100 \%$ oxygen was provided. During hyperbaric oxygen supplementation this further increased 2.4-fold, to 2.4 ATA.

nonlinear 3-element model of the input impedance of the aorta (Jellema et al., 1999). Mean arterial pressure (MAP) was the integral over one heart beat and the heart rate (HR) was the inverse of the pulse interval. Cardiac output (CO) was SV times HR. SVR was MAP divided by CO, in dyn $\cdot \mathrm{s} / \mathrm{cm}^{5}$. Pulse pressure (PP) was systolic BP (SBP) minus diastolic BP (DBP). All hemodynamic parameters were derived from the last minute of the measurements at baseline and at each oxygen dose. Time domain cross-correlation baroreflex sensitivity (xBRS) was calculated from the same intervals as the other parameters, using dedicated software (WinXBRS 2, BMEye, Amsterdam, The Netherlands; Westerhof et al., 2004). The xBRS was computed using beat-to-beat SBP and R-R interval, in a sliding $10 \mathrm{~s}$ window. Each instance that a correlation with a significance level of $p \leq 0.01$ was found the $x B R S$ value was recorded.

\section{Statistical Analysis}

Normal distribution of the data was verified using Levine's test and data are presented as mean \pm standard deviation, unless otherwise indicated. The within group responses to increasing $\mathrm{ppO}_{2}$ were assessed using general linear modeling. $P<0.05$ were considered significant. 


\section{RESULTS}

\section{Normobaric Oxygen Challenge (CKD Patients)}

SBP and DBP both increased with increasing oxygen supplementation from $128 \pm 24 / 72 \pm 19$ at baseline to 141 $\pm 23 / 80 \pm 21 \mathrm{mmHg}$ systolic/diastolic at a $\mathrm{ppO}_{2}$ of 1.0 ATA, $F_{(3,18)}=12.6, p<0.001$ for SBP and $F_{(3,18)}=8.8, p<0.001$ for DBP (Figures 3A,B). The pulse pressure increased as well, from $55 \pm 13$ to $61 \pm 11 \mathrm{mmHg}\left[F_{(3,18)}=5.8, p=0.002\right.$, Figure $\left.3 \mathrm{D}\right]$. $\mathrm{HR}\left[60 \pm 8 \mathrm{bpm}\right.$ at baseline; $58 \pm 6 \mathrm{bpm}$ at $1.0 \mathrm{ATA} \mathrm{ppO}_{2}, F_{(3,18)}$ $=25.1, p<0.001]$ and $\mathrm{CO}[5.0 \pm 1.3 \mathrm{~L} / \mathrm{min}$ at baseline; $4.6 \pm 1.1$ $\mathrm{L} / \mathrm{min}$ at $1.0 \mathrm{ATA} \mathrm{ppO}_{2}, F_{(3,18)}=3.6, p=0.02$ ] decreased during oxygen supplementation (Figures 3E,G). SVR increased from $1440 \pm 546$ to $1745 \pm 710 \mathrm{dyn} \cdot \mathrm{s} / \mathrm{cm}^{5},\left[F_{(3,18)}=4.3, p=0.009\right.$, Figure 3F]. xBRS remained unchanged with $13 \pm 13 \mathrm{~ms} / \mathrm{mmHg}$ at baseline and $15 \pm 12 \mathrm{~ms} / \mathrm{mmHg}$ at $1.0 \mathrm{ATA} \mathrm{ppO}_{2}\left[F_{(3,7)}=\right.$ $0.647 ; p=0.59$, Figure $3 \mathbf{H}]$.

\section{Hyperbaric Oxygen Challenge (CKD Patients)}

Due to the results of oxygen supplementation under normobaric conditions, the hyperbaric experiments were suspended for ethical reasons after studying four patients (and not carried out in the control subjects). When changing from a normobaric (1 ATA) to a hyperbaric condition (2.4 ATA, Figure 4), SBP and DBP where $121 \pm 17 / 70 \pm 16$ at baseline and $146 \pm 18 / 84 \pm 11$ mmHg systolic/diastolic at a $\mathrm{ppO}_{2}$ of 2.4 ATA (Figures 4A,B). Pulse pressure was $51 \pm 9$ at baseline and $62 \pm 13 \mathrm{mmHg}$ at 2.4 ATA $\mathrm{ppO}_{2}$ (Figure 4D). HR was $64 \pm 9 \mathrm{bpm}$ at baseline and $60 \pm 8 \mathrm{bpm}$ at $2.4 \mathrm{ATA} \mathrm{ppO}_{2}$ and $\mathrm{CO}$ was $4.2 \pm 1.3 \mathrm{~L} / \mathrm{min}$ at baseline and $3.6 \pm 0.4 \mathrm{~L} / \mathrm{min}$ at 2.4 $\mathrm{ATA} \mathrm{ppO}_{2}$ (Figures 4E,G). No further increase in SVR was observed during hyperbaric oxygen supplementation (Figure 4F). Changes in SBP did not correlate with eGFR $(R=0.013)$.

\section{Control Subjects}

During the normobaric oxygen challenge in the control group, SVR increased significantly from 903 at baseline to $985 \mathrm{dyn} \cdot \mathrm{s} / \mathrm{cm}^{5}$ at a $\mathrm{ppO}_{2}$ of $1.0 \mathrm{ATA}, F_{(3,7)}=11.6 ; p<0.001$ (Figure 3F). $\operatorname{SBP}\left[F_{(3,7)}=2.60 ; p=0.08\right]$, DBP $\left[F_{(3,7)}=1.33 ; p=0.29\right]$, $\operatorname{MAP}\left[F_{(3,7)}=1.28 ; p=0.31\right]$ and $\mathrm{PP}\left[F_{(3,7)}=2.07 ; p=\right.$ $0.13]$, did not change (Figures 3A-D), $\operatorname{HR}\left[F_{(3,7)}=13.0 ; p<\right.$ $0.001]$ and $\mathrm{CO}\left[F_{(3,7)}=6.73 ; p=0.002\right]$ decreased with oxygen supplementation (Figures 3E,G). xBRS remained unchanged $\left[F_{(3,7)}=0.884 ; p=0.47\right.$, Figure $\left.3 \mathbf{H}\right]$.

\section{DISCUSSION}

The findings of this study can be summarized as follows: (1) Oxygen supplementation causes a dose-dependent blood pressure increase among CKD patients. (2) This blood pressure increase is caused by an SVR increase. (3) The simultaneous HR decrease with unchanged baroreflex sensitivity indicates that the SVR increase is caused by a direct vascular effect of the increased plasma $\mathrm{ppO}_{2}$ rather than a response of the baroreflex.
Our results seem to contradict previous findings in CKD patients (Hering et al., 2007). Hering et al. found that in a similar experiment, exposing CKD patients to $100 \%$ oxygen resulted in a $30 \%$ reduction in muscle sympathetic nerve activity (Hering et al., 2007), whereas we find an increased systemic vasoconstriction. Upon closer inspection, their SNA decrease was accompanied by a slight increase in diastolic blood pressure-similar to what we found-which was not elaborated upon further. Instead, the analysis focussed on a decreased pulse pressure. However, this rise in diastolic blood pressure may be the key to explaining the decreased SNA during oxygen supplementation in CKD patients. Therefore, we need to consider the haemodynamic effects of hyperoxia in health with regard to baroreflex function.

In healthy humans, oxygen supplementation induces hyperoxic vasoconstriction as observed in our controls and previously reported data (Waring et al., 2003; Gill and Bell, 2004). This response is due to (1) the direct vasoconstrictive effect of plasma $\mathrm{pO}_{2}$ itself and (2) its ability to simultaneously hinder vasodilatation by reducing nitric oxide (NO) bioavailability (Waring et al., 2003; Gill and Bell, 2004). In contrast to sympathetically mediated vasoconstriction, hyperoxic vasoconstriction acts independent of baroreflex function (Whalen et al., 1965; Villanucci et al., 1990). CKD patients have an intact arterial baroreflex system (Eckberg and Sleight, 1992), therefore modulation of the baroreflex leads to changes in $\mathrm{HR}$ and sympathetic activation to occur simultaneously and in the same direction, i.e., HR increase and sympathetic vasoconstriction versus $H R$ decrease and sympathetic decrease (leading to vasodilation). However, in our experiment vasoconstriction is observed with a simultaneous decrease in HR during oxygen supplementation. This is indicative of a deactivating signal by the baroreflex, resulting in a reduction in HR. Based on the coupling of sympathetic activity and $\mathrm{HR}$, this explains the decrease in sympathetic activity while diastolic blood pressure increases due to direct oxygen driven and non-baroreflex mediated vasoconstriction (Hering et al., 2007).

To explain the blood pressure increase that we observed in CKD patients, we consider the ability of hyperoxia to decrease vasodilatory capacity by reducing NO bioavailability. Reduced NO bioavailability in CKD patients (similar to diabetic and hypertension patients; Al-Waili et al., 2006) may impede the attenuation of the hemodynamic effects of hyperoxic vasoconstriction (Endemann and Schiffrin, 2004; Martens and Edwards, 2011). Therefore, our data are most consistent with inadequate attenuation of hyperoxic vasoconstriction in patients with CKD-related endothelial dysfunction.

Thus, it appears that the hemodynamic response to hyperoxia is not uniquely affected in CKD patients. Instead, it seems that hyperoxic vasoconstriction induces an increase in blood pressure, leading to baroreflex deactivation with a reduction in systemic sympathetic tone. Our data (and in hindsight those from Hering et al.) do not support nor exclude the existence of a CKD-kidney specific hypoxic triggering of (either renal or extra-renal) chemo receptors. The overwhelming effects of oxygen on systemic vasoconstriction render the experimental set-up unsuitable to 

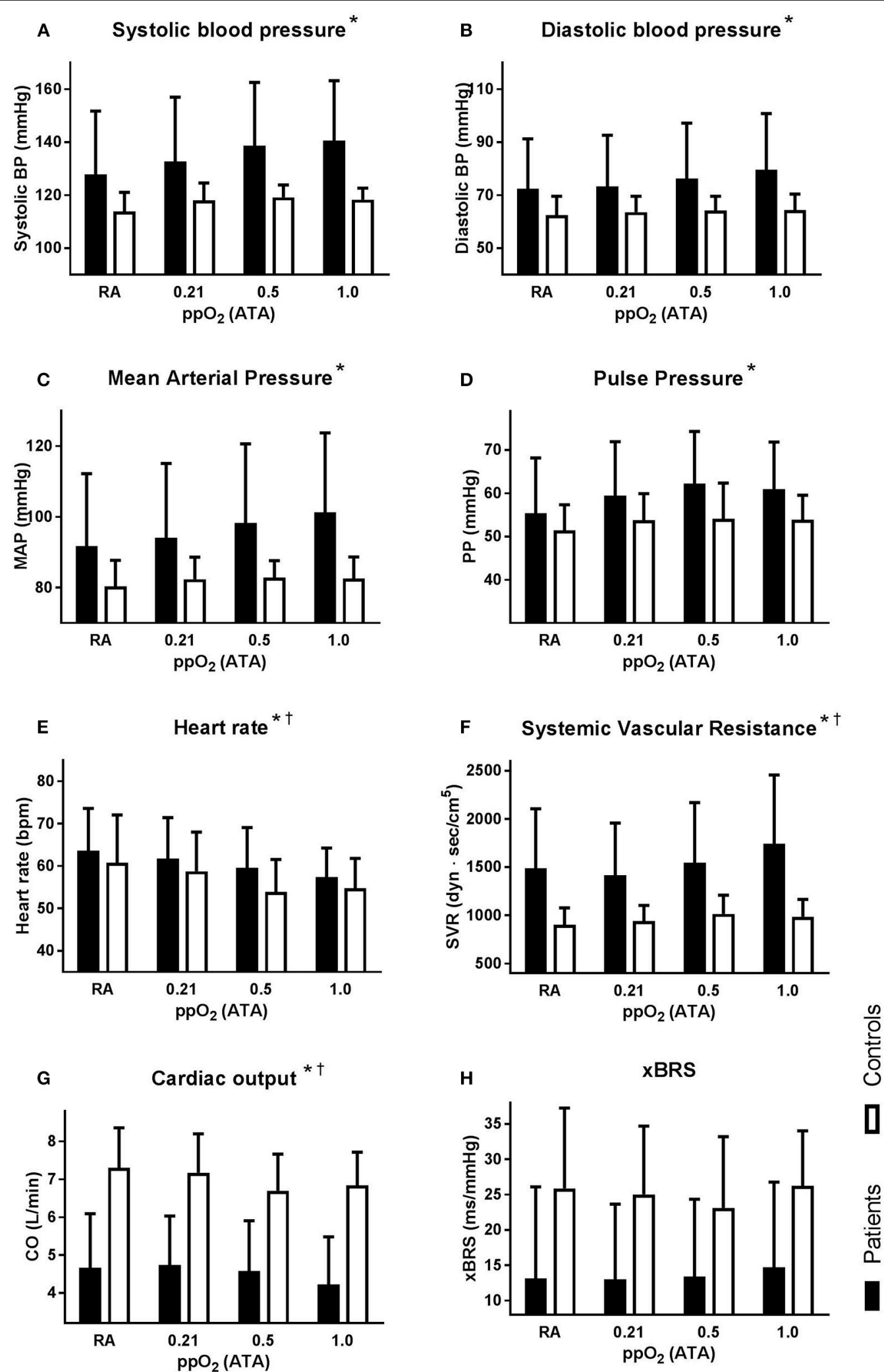

FIGURE 3 | Hemodynamic response to normobaric oxygen supplementation, for the patient (solid bars) and the young healthy controls (open bars). All graphs depict absolute mean $\pm S D$ at each condition: room air (RA), 21\% oxygen over a non-rebreathing mask (ppO 20.21 ATA), $50 \%$ oxygen (ppO 20.5 ATA), and $100 \%$ oxygen $\left(\mathrm{ppO}_{2} 1.0\right.$ ATA). Averages over the last minute of each condition for: (A) systolic blood pressure; (B) diastolic blood pressure; (C) mean arterial pressure (MAP); (D) pulse pressure (PP); (E) heart rate (HR); (F) systemic vascular resistance (SVR); (G) cardiac output (CO); (H) baroreflex sensitivity (xBRS). Designation of significant responses to oxygen supplementation in patients * and in controls ${ }^{\dagger}$. 


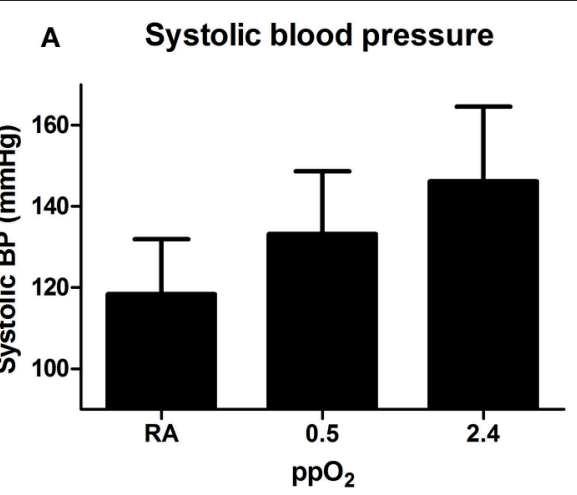

C Mean Arterial Pressure

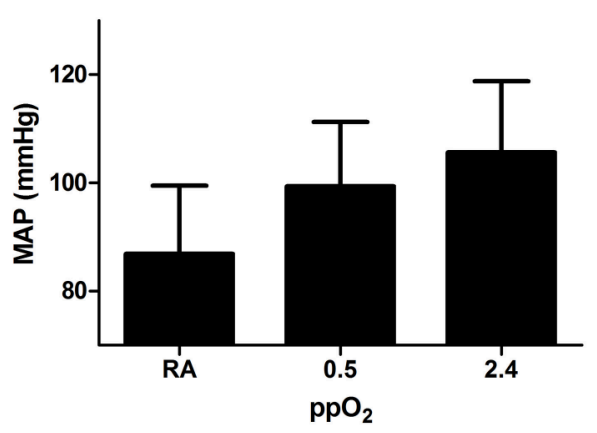

E

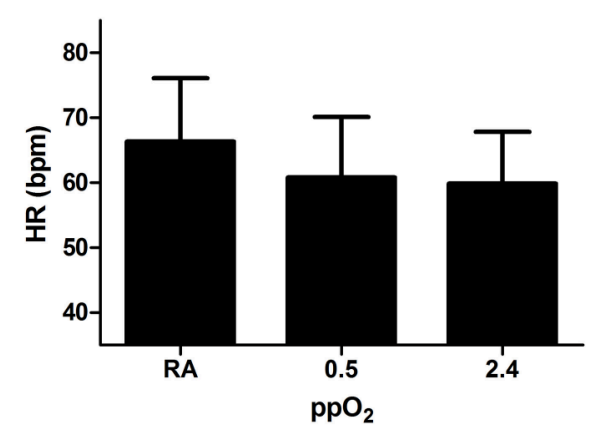

G Cardiac output

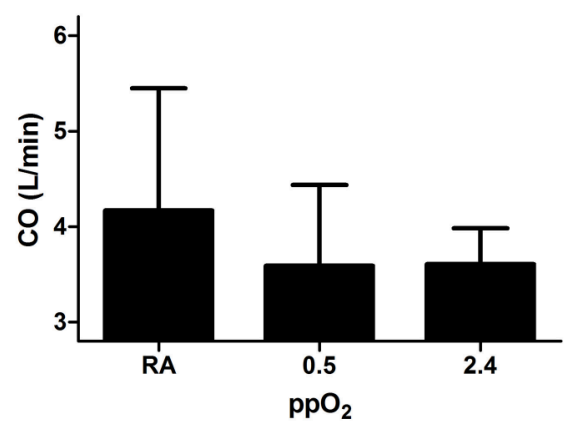

B Diastolic blood pressure

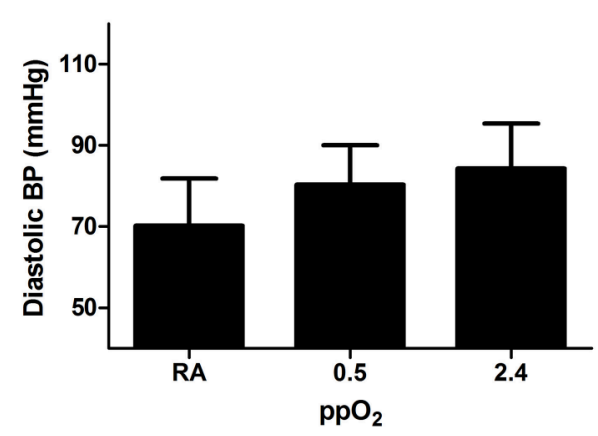

D Pulse Pressure

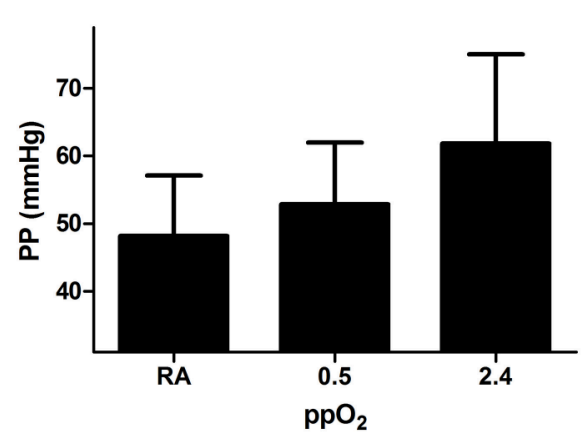

F Systemic Vascular Resistance

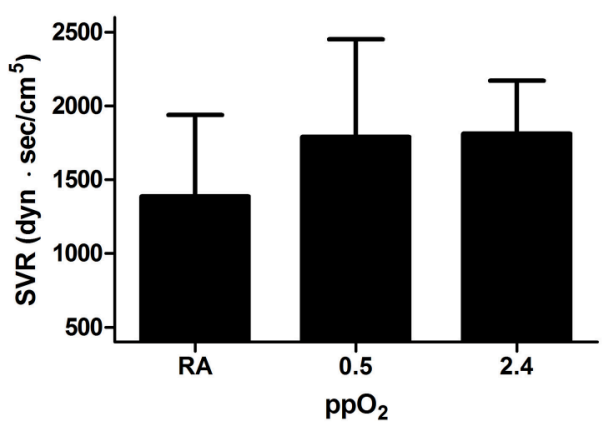

H xBRS

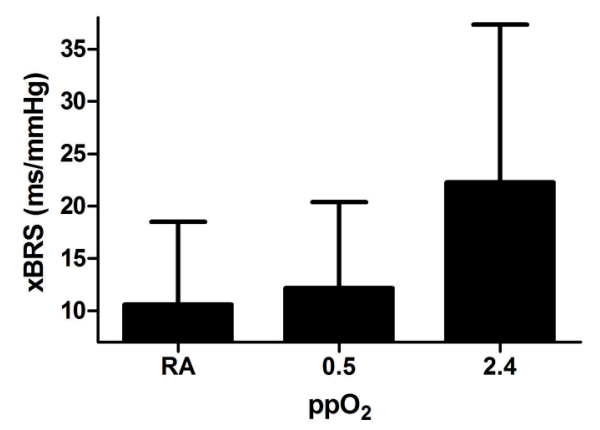

FIGURE 4 | Hemodynamic response to hyperbaric oxygen supplementation. All graphs depict absolute mean $\pm S D$ at each condition: room air (RA), hyperbaric RA ( $\left.\mathrm{ppO}_{2} 0.5 \mathrm{ATA}\right)$, and hyperbaric oxygen ( $\mathrm{ppO}_{2} 2.4$ ATA). Averages over the last minute of blood pressure registration at each condition of: (A) systolic blood pressure; (B) diastolic blood pressure; (C) mean arterial pressure (MAP); (D) pulse pressure (PP); (E) heart rate (HR); (F) systemic vascular resistance (SVR); (G) cardiac output (CO); (H) baroreflex sensitivity (xBRS). 
detect any possible subtle effects of kidney specific oxygenation on sympathetic outflow.

A possible clinical implication of these results is that oxygen supplementation might act as a cardiovascular stressor in CKD patients. Interestingly, this is in line with observations that oxygen supplementation in selected clinical patients is associated with worse outcome (Kones, 2011; Stub et al., 2015). Additionally, our study provides some more explanation on the lack of efficacy of catheter based renal denervation. The presumed decrease in SNA and blood pressure by oxygen supplementation in CKD patients was one of the founding principles of the pathophysiological rationale for renal sympathetic denervation (Schlaich et al., 2011; Davis et al., 2013). Eventually, renal sympathetic denervation showed not to have any effect on blood pressure, and specifically not in CKD patients (Bhatt et al., 2014). Our data question part of the founding rationale for renal sympathetic denervation.

Our study has several methodological limitations that merit discussion. First, patients continued the use of antihypertensive medication during the study. For ethical reasons these medications could not be fully withdrawn and was a compromise between taking out possible interfering factors versus patient risk. Our considerations were as follows: because of the specific effects on renal hemodynamics and oxygenation, ACE inhibitors and ARB's were stopped, as other antihypertensive drugs have a less (if any) pronounced effect on RAAS activity or intrarenal oxygen delivery. However, this may only have blunted the hemodynamic effects and thereby would not have affected our eventual conclusions, especially since patients acted as their own control. The same holds for the heterogeneous distributed baseline parameters (e.g., eGFR, smoking status, hemoglobin level) in our relatively small

\section{REFERENCES}

Al-Waili, N. S., Butler, G. J., Beale, J., Abdullah, M. S., Finkelstein, M., Merrow, M., et al. (2006). Influences of hyperbaric oxygen on blood pressure, heart rate and blood glucose levels in patients with diabetes mellitus and hypertension. Arch. Med. Res. 37, 991-997. doi: 10.1016/j.arcmed.2006.05.009

Bhatt, D. L., Kandzari, D. E., O’Neill, W. W., D’Agostino, R., Flack, J. M., Katzen, B. T., et al. (2014). A controlled trial of renal denervation for resistant hypertension. N. Engl. J. Med. 370, 1393-1401. doi: 10.1056/NEJMoa1402670

Converse, R. L. Jr., Jacobsen, T. N., Toto, R. D., Jost, C. M., Cosentino, F., FouadTarazi, F., et al. (1992). Sympathetic overactivity in patients with chronic renal failure. N. Engl. J. Med. 327, 1912-1918. doi: 10.1056/NEJM199212313272704

Davis, M. I., Filion, K. B., Zhang, D., Eisenberg, M. J., Afilalo, J., Schiffrin, E. L., et al. (2013). Effectiveness of renal denervation therapy for resistant hypertension: a systematic review and meta-analysis. J. Am. Coll. Cardiol. 62, 231-241. doi: 10.1016/j.jacc.2013.04.010

Eckardt, K. U., Bernhardt, W. M., Weidemann, A., Warnecke, C., Rosenberger, C., Wiesener, M. S., et al. (2005). Role of hypoxia in the pathogenesis of renal disease. Kidney Int. Suppl. 68, S46-S51. doi: 10.1111/j.1523-1755.2005.09909.x

Eckberg, D. L., and Sleight, P. (1992). Human Baroreflexes in Health and Disease. Oxford: Oxford University Press.

Endemann, D. H., and Schiffrin, E. L. (2004). Endothelial dysfunction. J. Am. Soc. Nephrol. 15, 1983-1992. doi: 10.1097/01.ASN.0000132474.50966.DA

Evans, R. G., Ince, C., Joles, J. A., Smith, D. W., May, C. N., O'Connor, P. M., et al. (2013). Haemodynamic influences on kidney oxygenation: clinical implications of integrative physiology. Clin. Exp. Pharmacol. Physiol. 40, 106-122. doi: 10.1111/1440-1681.12031 patient group. Secondly, we did not assess changes in $\mathrm{CO}_{2}$ partial pressure during oxygen supplementation. However, this has previously been shown not to be influenced by oxygen supplementation (Whalen et al., 1965). Also, the group of young healthy controls was not selected to be age matched, because it intended to verify the accuracy of our method. Others have reported upon the effects of hyperoxia in healthy elderly subjects previously (Whalen et al., 1965; Al-Waili et al., 2006). Lastly, the observers were not blinded but this was corrected by standardizing the time frame selection for analysis.

\section{CONCLUSIONS}

We have shown that oxygen supplementation in CKD patients increases blood pressure in a dose dependent fashion. This response is mediated by an increase in SVR, likely as the result of hyperoxic vasoconstriction independent of baroreflex function.

\section{AUTHOR CONTRIBUTIONS}

Study conception and design by RB, RH, ES, CK; Data acquisition, analysis and/or interpretation by $\mathrm{RB}, \mathrm{MÇ}, \mathrm{RH}, \mathrm{JL}$, $\mathrm{CK}$; Drafting of the manuscript by $\mathrm{RB}, \mathrm{CK}$; Revising by $\mathrm{MÇ}, \mathrm{RH}$, JL, ES, CK; Final approval of manuscript provided by $\mathrm{RB}, \mathrm{MÇ}$, RH, JL, ES, CK.

\section{FUNDING}

This project was funded by the Dutch Kidney Foundation (Project KJPB 12.029 to CP). CP is supported by the Netherlands Organization for Health Research and Development (ZonMw, Clinical Fellowship 40007039712461).

Ganz, W., Donoso, R., Marcus, H., and Swan, H. J. (1972). Coronary hemodynamics and myocardial oxygen metabolism during oxygen breathing in patients with and without coronary artery disease. Circulation 45, 763-768. doi: 10.1161/01.CIR.45.4.763

Gawish, A. E., Donia, F., Fathi, T., Al-Mousawi, M., and Samhan, M. (2010). It takes time after bilateral nephrectomy for better control of resistant hypertension in renal transplant patients. Transplant. Proc. 42, 1682-1684. doi: 10.1016/j.transproceed.2010.04.014

Getts, R. T., Hazlett, S. M., Sharma, S. B., McGill, R. L., Biederman, R. W., Marcus, R. J., et al. (2006). Regression of left ventricular hypertrophy after bilateral nephrectomy. Nephrol. Dial. Transplant 21, 1089-1091. doi: 10.1093/ndt/gfi321

Gill, A. L., and Bell, C. N. (2004). Hyperbaric oxygen: its uses, mechanisms of action and outcomes. QJM 97, 385-395. doi: 10.1093/qjmed/hch074

Hausberg, M. (2002). Sympathetic nerve activity in end-stage renal disease. Circulation 106, 1974-1979. doi: 10.1161/01.CIR.0000034043.16664.96

Hausberg, M., and Grassi, G. (2007). Mechanisms of sympathetic overactivity in patients with chronic renal failure: a role for chemoreflex activation? J. Hypertens. 25, 47-49. doi: 10.1097/HJH.0b013e3280119286

Hering, D., Zdrojewski, Z., Krol, E., Kara, T., Kucharska, W., Somers, V. K., et al. (2007). Tonic chemoreflex activation contributes to the elevated muscle sympathetic nerve activity in patients with chronic renal failure. J. Hypertens. 25, 157-161. doi: 10.1097/HJH.0b013e3280102d92

Herzog, C. A., Mangrum, J. M., and Passman, R. (2008). Sudden cardiac death and dialysis patients. Semin. Dial. 21, 300-307. doi: 10.1111/j.1525-139X.2008.00455.x

Imholz, B. P., Wieling, W., Van Montfrans, G. A., and Wesseling, K. H. (1998). Fifteen years experience with finger arterial pressure 
monitoring: assessment of the technology. Cardiovasc. Res. 38, 605-616. doi: 10.1016/S0008-6363(98)00067-4

Jellema, W. T., Wesseling, K. H., Groeneveld, A. B., Stoutenbeek, C. P., Thijs, L. G., and van Lieshout, J. J. (1999). Continuous cardiac output in septic shock by simulating a model of the aortic input impedance: a comparison with bolus injection thermodilution. Anesthesiology 90, 1317-1328. doi: 10.1097/00000542-199905000-00016

Kones, R. (2011). Oxygen therapy for acute myocardial infarction-then and now. A century of uncertainty. Am. J. Med. 124, 1000-1005. doi: 10.1016/j.amjmed.2011.04.034

Koomans, H. A., Blankestijn, P. J., and Joles, J. A. (2004). Sympathetic hyperactivity in chronic renal failure: a wake-up call. J. Am. Soc. Nephrol. 15, 524-537. doi: 10.1097/01.ASN.0000113320.57127.B9

Martens, C. R., and Edwards, D. G. (2011). Peripheral vascular dysfunction in chronic kidney disease. Cardiol. Res. Pract. 2011:267257. doi: 10.4061/2011/267257

Medina, A., Bell, P. R., Briggs, J. D., Brown, J. J., Fine, A., Lever, A. F., et al. (1972). Changes of blood pressure, renin, and angiotensin after bilateral nephrectomy in patients with chronic renal failure. Br. Med. J. 4, 694-696. doi: 10.1136/bmj.4.5842.694

Neumann, J., Ligtenberg, G., Klein, I. I., Koomans, H. A., and Blankestijn, P. J. (2004). Sympathetic hyperactivity in chronic kidney disease: pathogenesis, clinical relevance, and treatment. Kidney Int. 65, 1568-1576. doi: 10.1111/j.1523-1755.2004.00552.x

Park, J., Campese, V. M., and Middlekauff, H. R. (2008). Exercise pressor reflex in humans with end-stage renal disease. Am. J. Physiol. Regul. Integr. Comp. Physiol. 295, R1188-R1194. doi: 10.1152/ajpregu.90473.2008

Schlaich, M. P., Krum, H., Sobotka, P. A., and Esler, M. D. (2011). Renal denervation and hypertension. Am. J. Hypertens. 24, 635-642. doi: 10.1038/ajh.2011.35

Siddiqi, L., Joles, J. A., Grassi, G., and Blankestijn, P. J. (2009). Is kidney ischemia the central mechanism in parallel activation of the renin and sympathetic system? J. Hypertens. 27, 1341-1349. doi: 10.1097/HJH.0b013e32832b521b

Stub, D., Smith, K., Bernard, S., Nehme, Z., Stephenson, M., Bray, J. E., et al. (2015). Air versus oxygen in ST-segment-elevation myocardial infarction. Circulation 131, 2143-2150. doi: 10.1161/CIRCULATIONAHA.114.014494
Thomson, A. J., Webb, D. J., Maxwell, S. R., and Grant, I. S. (2002). Oxygen therapy in acute medical care. BMJ 324, 1406-1407. doi: 10.1136/bmj.324.7351.1406

Thukkani, A. K., and Bhatt, D. L. (2013). Renal denervation therapy for hypertension. Circulation 128, 2251-2254. doi: 10.1161/CIRCULATIONAHA.113.004660

van der Bel, R., Sliggers, B. C., van Houwelingen, M. J., van Lieshout, J. J., Halliwill, J. R., van Hulst, R. A., et al. (2016). A modified device for continuous noninvasive blood pressure measurements in humans under hyperbaric and/or oxygen-enriched conditions. Diving Hyperb. Med. 46, 38-42.

Villanucci, S., Di Marzio, G. E., Scholl, M., Pivorine, C., d'Adamo, C., and Settimi, F. (1990). Cardiovascular changes induced by hyperbaric oxygen therapy. Undersea Biomed. Res. 17(Suppl. 1):117.

Waring, W. S., Thomson, A. J., Adwani, S. H., Rosseel, A. J., Potter, J. F., Webb, D. J., et al. (2003). Cardiovascular effects of acute oxygen administration in healthy adults. J. Cardiovasc. Pharmacol. 42, 245-250. doi: 10.1097/00005344-200308000-00014

Westerhof, B. E., Gisolf, J., Stok, W. J., Wesseling, K. H., and Karemaker, J. M. (2004). Time-domain cross-correlation baroreflex sensitivity: performance on the EUROBAVAR data set. J. Hypertens. 22, 1371-1380. doi: 10.1097/01.hjh.0000125439.28861.ed

Whalen, R. E., Saltzman, H. A., Holloway, D. H. Jr., McIntosh, H. D., Sieker, H. O., and Brown, I. W. Jr. (1965). Cardiovascular and blood gas responses to hyperbaric oxygenation. Am. J. Cardiol. 15, 638-646. doi: 10.1016/0002-9149(65)90350-4

Conflict of Interest Statement: The authors declare that the research was conducted in the absence of any commercial or financial relationships that could be construed as a potential conflict of interest.

Copyright (C) 2017 van der Bel, Çalişkan, van Hulst, van Lieshout, Stroes and Krediet. This is an open-access article distributed under the terms of the Creative Commons Attribution License (CC BY). The use, distribution or reproduction in other forums is permitted, provided the original author(s) or licensor are credited and that the original publication in this journal is cited, in accordance with accepted academic practice. No use, distribution or reproduction is permitted which does not comply with these terms. 